\title{
The story of a lost guidewire
}

\author{
D Bagaria, MS; L Kaman, MS, MRCS
}

Department of General Surgery, Postgraduate Institute of Medical Education and Research, Chandigarh, India

Corresponding author: D Bagaria (dr_bagaria@yahoo.co.in)

Seldinger's technique is widely used to place central venous and arterial catheters, and is generally considered to be safe. The technique does, however, have multiple potential risks. Guidewire-related complications are rare but potentially serious. We describe a case of a lost guidewire during central venous catheter insertion followed by retrieval by an interventional radiologist, and outline measures that can be taken to prevent such complications.

S Afr J Crit Care 2014;30(2):58. DOI:10.7196/SAJCC.195



A 67-year-old male patient presented as an emergency with shock. The patient responded poorly to resuscitation, so central line placement was planned for central venous pressure (CVP) monitoring and for inotropic support. After skin disinfection and draping, the right infraclavicular subclavian route was attempted. Venous blood was aspirated and the guidewire was introduced smoothly. The cannula was removed with the guidewire in situ and the dilator was advanced to create a track. While advancing the dilator, the end of the guidewire accidently slipped from the operator's hand. On withdrawal of the dilator, the guidewire was missing. A small incision was made at the insertion site to find the end of the guidewire in the subcutaneous tissue, but this was unsuccessful. A mobile chest $\mathrm{X}$-ray revealed the guidewire passing from the right subclavian vein, through the heart to the inferior vena cava (Fig. 1). An interventional radiologist removed the guidewire via the femoral vein using a gooseneck snare. The patient recovered uneventfully.

\section{Discussion}

Central venous access is an important strategy in the management of critically ill patients for CVP measurement, the infusion of drugs and nutrients best administered centrally, and the sampling of central venous blood. This is, however, an invasive procedure with complication rates as high as $12 \%$ being reported. ${ }^{[1]}$ The embolisation of a guidewire is a rare but reported complication. In most cases, this occurs when the operator does not ensure that the proximal end of the guidewire is protruding from the catheter hub before inserting the catheter over the guidewire. In this case, the wire was lost with the insertion of the dilator, showing that this too is a hazardous step in the procedure.

Lost guidewires must be retrieved and the method of choice is intervention radiology, ${ }^{[2,3]}$ although open surgical procedure is also reported. ${ }^{[4]}$ Usually retrieval is uncomplicated, but complications might arise due to fragment embolisation or from the formation of a thrombus over the guidewire. ${ }^{[2,3]}$

\section{Safety tips to avoid loss of the guidewire}

- Avoid distractions during the catheter insertion.

- The length of the guidewire should always exceed that of the catheter.

- Never let go of the guidewire, which should be held either at the proximal end or at the skin puncture site, during the dilatation step and during the catheter insertion.

- After the procedure, always check the presence of the used guidewire in the procedure tray.

- As a routine, an early postprocedure X-ray should be performed to check for a lost guidewire and other complications.

- As measured by Andrews et al., ${ }^{[5]}$ the distance between skin puncture site and cavo-atrial junction via various approaches is between $16 \mathrm{~cm}$ and 21 $\mathrm{cm}$; we advise not to insert the guidewire beyond that required length.

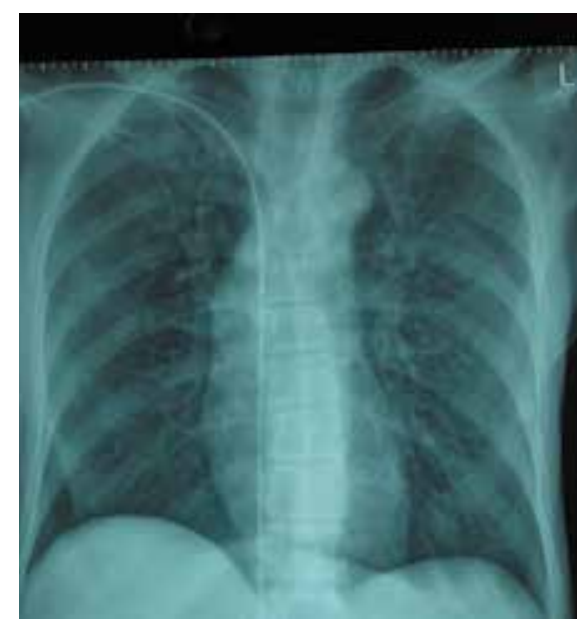

Fig. 1. Chest $X$-ray revealing the guidewire passing from the right subclavian vein, through the heart to the inferior vena cava.

Written informed consent for publication of this case report was obtained from the patient's next of kin.

\footnotetext{
References

1. Mansfield PF, Hohn DC, Fornage BD, Gregurich MA Ota DM. Complications and failures of subclavian-vein catheterization. N Engl J Med 1994;331(26):1735-1738. [http://dx.doi.org/10.1056/NEJM199412293312602]

2. Yedlicka JW Jr, Carlson JE, Hunter DW, Castañeda-Zúñiga WR, Amplatz K. Nitinol gooseneck snare for removal of foreign bodies: Experimental study and clinical evaluation. Radiology 1991;178(3):691-693. [http://dx.doi.org/10.1148/ radiology.178.3.1994404]

3. Dondelinger R, Lepoutre B, Kurdziel J. Percutaneous vascular foreign body retrieval: Experience of an 11-year period. Eur J Radiol 1991;12(1):4-10

4. Omar HR, Fathy A, Mangar D, Camporesi E. Missing the guidewire: An avoidable complication. Int Arch Med 2010;3:21. [http://dx.doi.org/10.1186/1755-7682-3-21]

5. Andrews RT, Bova DA, Venbrux AC. How much guidewire is too much? Direct measurement of the distance from subclavian and internal jugular vein access sites to the superior vena cava-atrial junction during central venous catheter placement. Crit Care Med 2000;28(1):138-142.
} 